\title{
Idiopathic Granulomatous Lobular Mastitis - Report of 43 Cases from Iran; Introducing a Preliminary Clinical Practice Guideline
}

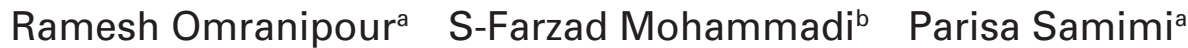 \\ ${ }^{a}$ Cancer Institute, \\ ${ }^{b}$ Farabi Hospital, Tehran University of Medical Sciences, Tehran, Iran
}

\begin{abstract}
Keywords
Idiopathic granulomatous lobular mastitis .

Multidisciplinary approach - Treatment strategies .

Clinical practice guidelines · Iran · Milk extravasation .

Breast-feeding · Relapse
\end{abstract}

\section{Summary}

Background: We aimed to report a large series of idiopathic granulomatous lobular mastitis (IGLM) from Iran and sketch preliminary clinical practice guidelines (CPG) for approaching an inflammatory breast mass. Patients and Methods: In a retrospective records review, 43 consecutive IGLM cases were studied. Data on baseline, clinical, imaging, and pathologic characteristics were collected. Results: The mean age of the women was 33.5 years. All but 1 were married and had given birth. $16 \%$ had a cancer-like presentation. Inflammatory signs, architectural distortion, and a nodular pattern were the most common findings clinically, mammographically and ultrasonographically, respectively. $29.5 \%$ of the pathological reports indicated necrosis which was more common in younger subjects $(p=0.016)$; microabscesses were associated with a shorter lactation course $(p=0.006)$. Corticosteroids had been used as the initial treatment modality in $51 \%$, immunosuppressive agents had not been administered, and a $16 \%$ relapse rate was recorded. We recognized the need for a multidisciplinary approach covering radiology, oncology, and surgery to best handle diagnostic and therapeutic issues and manage relevant infections as well as the major differential diagnosis, i.e. malignancy. Conclusion: We hypothesized that a shorter lactation period may cause more milk stasis and extravasation and be contributory to IGLM. CPGs are needed to incorporate the needed multidisciplinary approach and to standardize IGLM care. We present one such guideline.

\section{Schlüsselwörter}

Idiopathische granulomatöse lobuläre Mastitis .

Multidisziplinäres Vorgehen · Behandlungsstrategien .

Klinische Praxisrichtlinien · Iran · Milchaustritt ins Gewebe . Stillen · Rezidiv

\section{Zusammenfassung}

Hintergrund: Unser Ziel war es, über eine große Serie idiopathischer granulomatöser lobulärer Mastitis (IGLM) aus dem Iran zu berichten und vorläufige klinische Praxisrichtlinien für das Vorgehen bei inflammatorischen Brustknoten zu entwerfen. Patientinnen und Methoden: Die Krankenakten von 43 konsekutiven IGLM-Fällen wurden untersucht. Daten zu Baseline-, klinischen, Bildgebungs- und pathologischen Merkmalen wurden gesammelt. Ergebnisse: Das mittlere Alter der Patientinnen war 33,5 Jahre. Bis auf eine Patientin waren alle verheiratet und hatten eigene Kinder. $16 \%$ hatten eine krebsähnliche Läsion. Entzündungsmerkmale, architektonischen Distorsion bzw. ein noduläres Erscheinungsbild waren die häufigsten klinischen, mammographischen bzw. ultrasonographischen Symptome. 29,5\% der pathologischen Berichte gaben Hinweise auf das Vorliegen von Nekrosen, insbesondere bei jüngeren Patientinnen $(p=0,016)$; Mikroabszesse waren mit einer kürzeren Stillperiode assoziiert ( $p=0,006)$. Kortikosteroide waren als initiale Behandlungsmodalität bei $51 \%$ der Patientinnen eingesetzt worden, Immunsuppressiva waren nicht zum Einsatz gekommen, und die berichtete Rezidivrate war $16 \%$. Wir erkannten die Notwendigkeit einer multidisziplinären Vorgehensweise unter Einbeziehung von Radiologie, Onkologie und Chirurgie, um diagnostische und therapeutische Fragestellungen optimal angehen zu können und relevante Infektionen sowie bösartige Tumoren als hauptsächliche Differentialdiagnose managen zu können. Schlussfolgerung: Wir stellen die Hypothese auf, dass eine kürzere Stillperiode zu häufigerem Milchstau und Milchaustritt ins Gewebe führt und damit zur Entstehung von IGLM beiträgt. Praxisrichtlinien müssen aufgestellt werden, um die notwendige multidisziplinäre Vorgehensweise einzuführen und die Versorgung von IGLM-Fällen zu standardisieren. Wir stellen hier eine solche Richtlinie vor.

\section{KARGER \\ Fax +497614520714 \\ Information@Karger.com}

www.karger.com (c) 2013 S. Karger GmbH, Freiburg

$1661-3791 / 13 / 0086-0439 \$ 38.00 / 0$

Accessible online at:

www.karger.com/brc
Parisa Samimi, MD

Department of Surgical Oncology

Cancer Institute

Imam Khomeini Hospital Complex

Keshavarz Blvd, Tehran, Iran

parisa.samimi@gmail.com 


\section{Introduction}

Idiopathic granulomatous lobular mastitis (IGLM) is a rare relapsing inflammatory pseudotumor which is commonly mistaken for malignancy $[1,2]$. It presents as an ill-defined indurated and relatively large mass, commonly in the upper outer quadrant or subareolar zone of the breast, typically in the reproductive post-childbearing period [3]. The mass is tender and may be associated with nipple retraction, peau d'orangelike changes, and an overlying erythematous and/or ulcerated skin. These features make the differential diagnosis challenging [3, 4]. Ultrasonographic, mammographic, and even magnetic resonance imaging findings are not pathognomonic. Fine needle aspiration cytology is practiced, but in nearly all cases core needle (or open) biopsy becomes mandatory $[4,5]$. There is no consensus about the management of IGLM. The relapsing nature is sometimes frustrating and the cosmetic sequelae of surgical excision are unwelcome. The aim of the current study is to report a relatively large series of IGLM from Iran and to sketch a preliminary clinical guideline for approaching an inflammatory breast mass.

\section{Patients and Methods}

In a retrospective study, records of 43 cases of confirmed IGLM were reviewed (Breast Cancer Clinic, Cancer Institute, Tehran; 20062012). Data on baseline, clinical, imaging, and pathologic characteristics were collected. The setting was a cancer referral center in the Capital Tehran, and the patients had a minimum follow-up of 6 months (median 16 months). Meticulous breast examination including the axillary region had been performed. The mentioned signs in the clinical records were collected. Mammography had been routinely carried out for the cases 35 years of age or older. An ultrasonography and fine needle aspiration had been variably performed, but the definitive diagnosis had been reached either through 14-gauge core needle biopsy or surgical excision and pathologic confirmation. In cases of suspicion for tuberculosis and bacterial infection, Ziehl-Neelsen and gram staining had been carried out. A tuberculin skin test had been ordered likewise. We encountered a single case of tuberculosis which was excluded from the series of 44 cases. Non-parametric statistical testing (Mann-Whitney $U$ test) was performed to explore the relationship between relapse and pathologic features with potential baseline and clinical course factors. Records were coded and kept anonymous.

\section{Results}

The mean age of the patients was 33.5 years (range $24-49$ years), excluding a single woman of 55 years of age. $92 \%$ of the patients were in the reproductive period, and $8 \%$ were in the perimenopause ( $>45$ years of age). The mean of the reported age at menarche was 14 years (range $12-16$ years). All but 1 case were married, had given birth (median 1 child, range $0-5$ children), and had a history of breastfeeding (mean 30 months, range $0-120$ months). None of the patients had a positive family history of breast cancer. The right breast was affected in $44 \%$ and the left breast in $56 \%$ ( 2 cases were bilateral). The median period of symptom-to-referral was 2 months, but the range was up to 4 years.

The cases presented with a variety of sign and symptom complexes (table 1). The presentation in 7 (16\%) cases was suggestive of cancer, and $78 \%$ had a history of empiric antibiotic treatment (oral cloxacilin or cephalexin for 10 days). In those who had had a mammogram (age $>35$ years), architectural distortion, nodular lesions, and asymmetric density were reported in descending order. Sonography was abnormal in $95 \%$ of cases; a nodular pattern and (large or small) hypoechoic spaces were reported (table 1). A biopsy was taken within the first month of referral in almost all cases (open biopsy $43.5 \%$, core biopsy $56.5 \%$ ). The diagnosis was made by detection of granulomatous lesions (aggregates of epithelioid cells) in a ductolobular configuration. It was notable that more than half of the pathological reports documented (micro)abscesses, and in a third of all patients necrosis was observed. $45 \%$ of cases had a white blood cell count of above $10,000 / \mathrm{mcl}$.

A total of $22(51 \%)$ cases were initially treated with systemic steroids, and the remaining patients underwent surgical resection as the initial modality. $90 \%$ of the cases were symptom-free at the last follow-up, and in the remaining 4 cases the inflammation had subsided significantly. 5 (11.5\%) cases of the steroid-treated group needed later surgical intervention, in some cases despite repeated courses of steroids. Of the $16 \%$ patients who had recurrences, one third was complicated by fistula formation necessitating surgical intervention.

Table 1. Clinical, imaging, and pathologic findings of idiopathic granulomatous lobular mastitis in our series (figures rounded; cases may have been listed in more than 1 category)

\begin{tabular}{|c|c|c|c|}
\hline Clinical presentation & $\begin{array}{l}\text { Mammographic findings } \\
\text { (14 cases) }\end{array}$ & $\begin{array}{l}\text { Sonographic findings } \\
\text { ( } 39 \text { cases) }\end{array}$ & Pathologic findings \\
\hline $\begin{array}{l}\text { Mass } 57 \% \\
\text { Suggestive for malignancy } 16 \%{ }^{a} \\
\text { Inflammatory signs } 34 \% \\
\text { Fistula } 9 \%\end{array}$ & $\begin{array}{l}\text { nodular lesion } 21.5 \% \\
\text { architectural distortion } 28.5 \% \\
\text { asymmetric density } 14 \%\end{array}$ & $\begin{array}{l}\text { nodular pattern } 79.5 \% \\
\text { hypoechoic spaces } 28 \%\end{array}$ & $\begin{array}{l}\text { multinucleated giant cells } 67 \% \\
\text { (micro)abscess formation } 53 \% \\
\text { mononuclear infiltration } 79.5 \% \\
\text { neutrophilic infiltration } 57.5 \% \\
\text { necrosis } 29.5 \% \\
\text { leukocytosis } 45 \%\end{array}$ \\
\hline
\end{tabular}

${ }^{\mathrm{a}}$ Including induration, skin retraction, ill-defined margins. 
Notably, necrosis was more frequently reported in younger patients (mean 29 vs. 34 years; $p=0.016$ ). Patients whose pathological reports indicated microabscess formation had a shorter history of lactation (19 vs. 37 months; $p=0.006$ ). Relapse was not correlated with the method of biopsy, history of antibiotic treatment, mammographic and ultrasonographic findings, age, and gynecologic history (all p >0.05).

\section{Discussion}

Recently, several series of IGLM were published in the international literature [6-9]. It is not known whether there is a real epidemic of the condition, or simple awareness and better reporting have caused this outbreak. We know that in recent decades the incidence of autoimmune diseases has been on the rise [10]. In the case of IGLM, changes in reproductive and lactation behavior might have contributed to this (fig. 1).

The characteristics of our cases were generally similar to those of previous reports. For instance, almost all patients were of a reproductive and childbearing age, and the mean age was consistent with previous reports $[9,11]$; only 1 of our cases was older than 50 years. All but 2 of our patients had a history of pregnancies and breastfeeding. This is compatible with the fact that IGLM mostly happens in the first few years following pregnancy or in those with a history of contraceptive use [12].

Fig. 1. Hypothetical pathogenesis of idiopathic ('milk-induced autoimmune') granulomatous lobular mastitis.
Clinical, mammographic, and sonographic findings (table 1) emphasize that through clinical and imaging studies one cannot differentiate IGLM from breast cancer [13, 14]. Mammographic findings in our series did not show the most characteristics signs of cancer, i.e. irregular or branching calcification [15], but architectural distortion and nodular lesions were seen. We documented relatively fewer asymmetric densities [16]. Sonography findings were similar to previous reports [16] but were also not characteristic as they included hypoechoic spaces and nodular lesions both of which are frequently observed in malignancy as well; however, cancerous lesions are less well-defined and more heterogeneous.

The implication is that we have to include IGLM as an important entity in the differential diagnosis of breast cancer, at least in referral centers, in order to prevent unnecessary wide excision. The broader list covers cystic neutrophilic granulomatous mastitis (in which the gram-positive bacillus Corynebacterium is involved), tuberculous mastitis, sarcoidosis, and Wegener's disease. Among the patients referred to us, a single tuberculous case was diagnosed and successfully treated.

It is noteworthy that 3 of our cases had coincident or previous erythema nodosum. The association of IGLM with other autoimmune phenomena has already been well described [11], and this emphasizes the necessity for both a systemic survey and a multidisciplinary approach in the management of this condition [13]. Due to the retrospective nature of this study, we did not have access to enough ordered lab tests for parameters such as erythrocyte sedimentation rate, C-reactive protein, rheumatoid factor, and antinuclear antibody [11]. However, the common presence of leukocytosis in our series points to the systemic nature of the condition, and we acknowledge that the patients with suspected IGLM require a serologic survey (table 2 and fig. 2). This is relevant for both the identification of coincidental rheumatologic disease and the monitoring of disease activity and response to treatment.

In histopathology, non-necrotizing granulomas (along with (multinucleated) giant cells) and 'lobulocentric' [17] arrange-

Table 2. Preliminary Clinical Practice Guidelines for Approaching Inflammatory Breast (Pseudo)Tumors

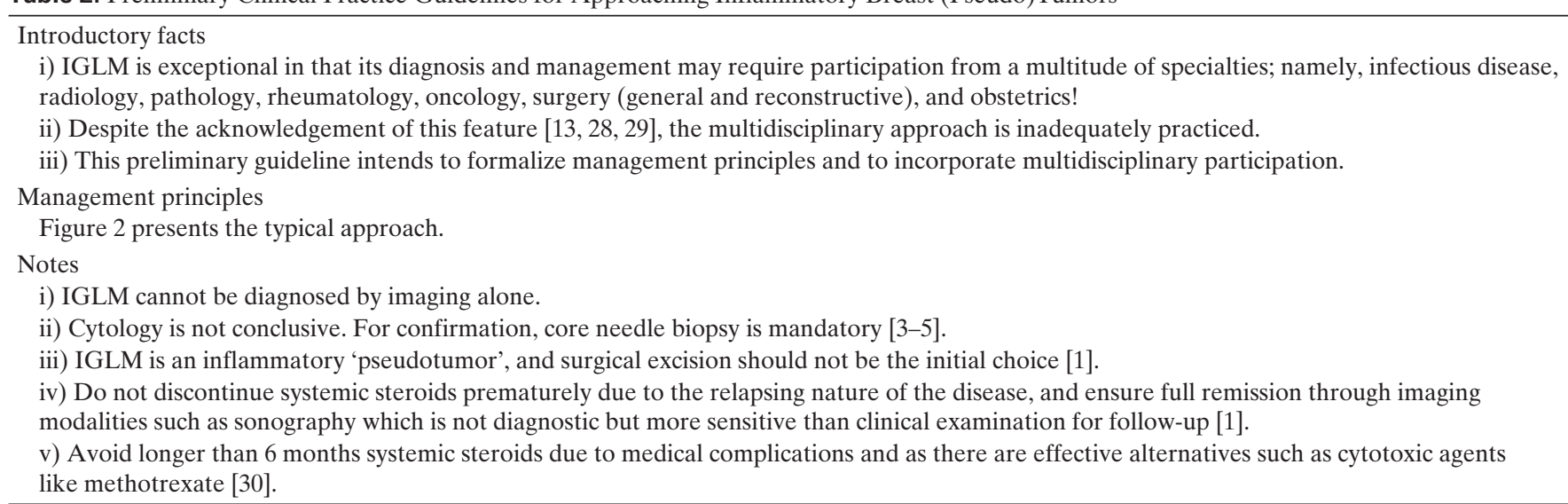




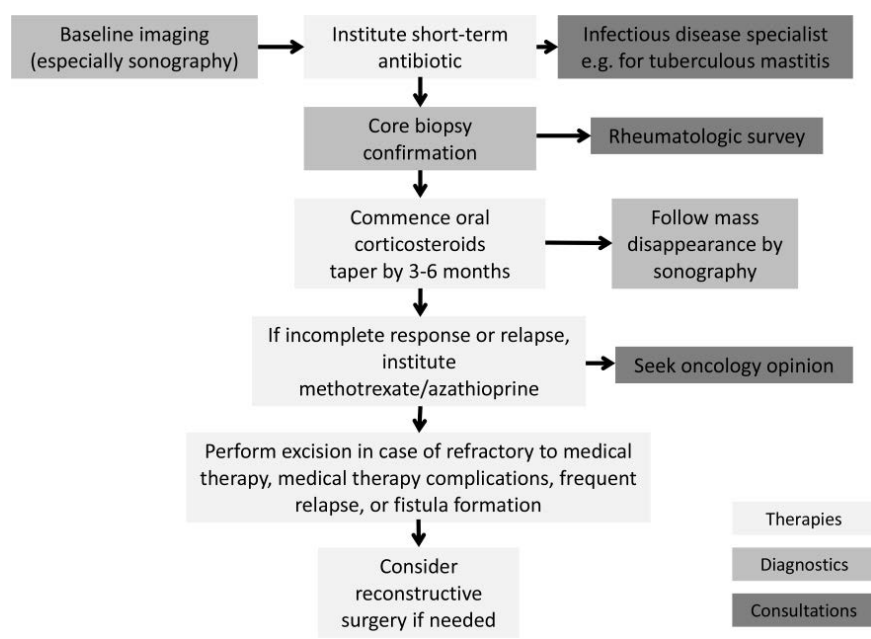

Fig. 2. Multidisciplinary approach to inflammatory breast mass; focused on idiopathic granulomatous lobular mastitis led by a general surgeon.

ment (with intact ductolobular architecture) are pathognomonic. However, this is not always the case; in our series necrosis was present in a sizable proportion of the patients $(29.5 \%)$.

Granulomas are not characteristic per se, and in order to differentiate the aforementioned entities, ancillary tests are required. One may state that IGLM clinically resembles cancer, and pathologically tuberculous mastitis. In the case of tuberculous mastitis, there is more fibrosis and eosinophils, and (caseation) necrosis can be seen [6,18]. In IGLM, however, granulomas are admixed with neutrophils and plasma cells. This is a feature of the IGLM histopathology, i.e. 'mixed' inflammatory infiltration (table 1). Some reports still link IGLM to Corynebacterium infection [19-21]; however, as was shown in our cases, in IGLM mononuclear cells are comparatively more common than neutrophils (table 1) and vice versa. It is noteworthy that in none of our cases calcification had been reported, and calcification has remained as a major differentiating factor between cancer and IGLM.

More frequent observations of necrosis in younger cases emphasize the role of immune responses. Microabscess formation in women with shorter lactation history brings to mind milk stasis as a contributing factor. As is illustrated in figure 1 , milk interstitial extravasation and development of autoimmunity seem to form the key pathogenic pathway [21]. Hence, the authors recommend the term 'milk-induced autoimmune' to be used instead of 'idiopathic' (granulomatous lobular) mastitis.

Some authorities argue that in the case of reconstructive surgery, implants are best avoided as they themselves may act as foreign bodies and trigger further granulomatous inflammation [21] (fig. 2).

It should be noted that our pathologic reports were not made in a consistent and systematic fashion; hence, the relative frequency of the documented features (table 1) would be largely suggestive.
No uniform therapeutic protocol has been established for IGLM [10]. Surgical excision aiming at total removal was the traditional approach [22], but today the likely autoimmune nature [10] has made corticosteroids the mainstay initial treatment [23]. Oral steroids are effective and control the lesions in most cases. However, the disease is frequently recurrent and sometimes refractory, and steroid-sparing agents would be needed. Surgical resection is occasionally inevitable [24]. Generally, patients need a course of 3-6 months of systemic corticosteroids to achieve remission or cure [1]. An initial empiric antibiotic treatment is irresistible and was performed in $78 \%$ of our cases. We then put our patients on low-dose steroids (none of the patients required more than $35 \mathrm{mg} /$ day to achieve a remission) and tapered treatment within 6 months. We finally achieved $90 \%$ remission or cure. Relapse and longterm steroid complications are the challenges of IGLM, and some have advocated methotrexate and azathioprine as maintenance modalities. We had a $16 \%$ relapse rate which is not unusual; relapse has been reported from as low as $8 \%$ to $23 \%$ and higher $[25,26]$. The variation can be attributed to different follow-up and the frequency of resorting to surgical excision as the primary intervention. One additional cause for relapse might be that the disease is not completely in remission while steroids are being discontinued. Studies have shown that sonography has the best sensitivity in following the disappearance of the lesion (as compared with magnetic resonance imaging and clinical examination) [1]. We did not use methotrexate and azathioprine despite their usefulness as reported in the literature. Cytotoxic agents not only spare steroid complications but also reduce the number of indications for excision and the need for reinstitution of steroids [13, 24]. The authors acknowledge that a closer relationship should have been established with the oncological team.

Mastectomy is best avoided in IGLM [3] but still has its own indications for abscess and fistula formation, persistent wound infection, and refractory cases. $44 \%$ of our patients underwent surgery as the primary intervention, and $11.5 \%$ of the remaining eventually received surgical intervention following medical treatment (collectively, 55.5\%). It should be noted that the classical approach of complete surgical excision (with or without steroids) [27] is now being replaced by primary medical therapy (steroids and immunosuppressive agents) [1] (our approach also evolved from primary surgery to primary medical treatment in the time course of the study).

In conclusion, IGLM should be included in the differential diagnosis of breast mass in patients of childbearing age, specifically in the years following pregnancy. A systemic survey needs to be carried out in order to best differentiate and diagnose the relevant infectious and coincident autoimmune entities. Diagnostic and therapeutic issues and the major differential diagnosis, i.e. malignancy, mandate a multidisciplinary approach covering radiology, rheumatology, oncology, gynecology, and surgery. We have drafted a preliminary clinical decision-making guideline for IGLM (table 2 and fig. 2). 


\section{Acknowledgment}

The authors would like to thank Dr. Najafi for case referral and Ms. Bagheri who helped us in record retrieval.

\section{Disclosure Statement}

No funding was made available for this study, and the authors do not have competing interests.

\section{References}

1 Sakurai K, Fujisaki S, Enomoto K, Amano S, Sugitani M: Evaluation of follow-up strategies for corticosteroid therapy of idiopathic granulomatous mastitis. Surg Today 2011;41:333-7.

$\checkmark 2$ Takano J, Prialé P: Idiopathic chronic granulomatous mastitis: a case report. Rev Peru Med Exp Salud Publica 2010;27:635-7.

-3 Naraynsingh V, Hariharan S, Dan D, Harnarayan P, Teelucksingh S: Conservative management for idiopathic granulomatous mastitis mimicking carcinoma: case reports and literature review. Breast Dis 2010;31:57-60.

4 Erozgen F, Ersoy YE, Akaydin M, Memmi N, Celik AS, Celebi F, Guzey D, Kaplan R: Corticosteroid treatment and timing of surgery in idiopathic granulomatous mastitis confusing with breast carcinoma. Breast Cancer Res Treat 2010;123:447-52.

$\checkmark 5$ Heer R, Shrimankar J, Griffith CD: Granulomatous mastitis can mimic breast cancer on clinical, radiological or cytological examination: a cautionary tale. Breast 2003;12:283-6.

-6 Lacambra M, Thai TA, Lam CC, Yu AM, Pham HT, Tran PV, Law BK, Van Nguyen T, Pham DX, Tse GM: Granulomatous mastitis: the histological differentials. J Clin Pathol 2011;64:40511.

7 Hugon-Rodin J, Plu-Bureau G, Hugol D, Gompel A: Management of granulomatous mastitis: a series of 14 patients. Gynecol Endocrinol 2012;28:921-4.

$>8$ Afridi SP, Memon A, Shafiq-ur-Rahman, Memon A: Granulomatous mastitis: a case series. J Coll Physicians Surg Pak 2010;20:365-8.

9 Kok KY, Telisinghe PU: Granulomatous mastitis: presentation, treatment and outcome in 43 patients. Surgeon 2010;8:197-201.

10 Miller FW, Alfredsson L, Costenbader KH, Kamen DL, Nelson LM, Norris JM, De Roos AJ: Epidemiology of environmental exposures and human autoimmune diseases: findings from a
National Institute of Environmental Health Sciences Expert Panel Workshop. J Autoimmun 2012; 39:259-71.

-11 Ozel L, Unal A, Unal E, Kara M, Erdoğdu E, Krand O, Güneş P, Karagül H, Demiral S, Izzet Titiz M: Granulomatous mastitis: is it an autoimmune disease? Diagnostic and therapeutic dilemmas. Surg Today 2012;42:729-33.

12 Hovanessian Larsen LJ, Peyvandi B, Klipfel N, Grant E, Iyengar G: Granulomatous lobular mastitis: imaging, diagnosis, and treatment. AJR Am J Roentgenol 2009;193:574-81.

13 Peña-Santos G, Ruiz-Moreno JL: Idiopathic granulomatous mastitis treated with steroids and methotrexate. Ginecol Obstet Mex 2011;79:373-6.

14 Cabrera G, Medina R: (Idiopathic granulomatous mastitis; a benign lesion with malignant clinicalradiological characteristics). Radiologia 2013;55: 90-2.

15 Tse GM, Tan PH, Pang AL, Tang AP, Cheung HS: Calcification in breast lesions: pathologists' perspective. J Clin Pathol 2008;61:145-51.

16 Dursun M, Yilmaz S, Yahyayev A, Salmaslioglu A, Yavuz E, Igci A, Acunas G, Tunaci M: Multimodality imaging features of idiopathic granulomatous mastitis: outcome of 12 years of experience. Radiol Med 2012;117:529-38.

17 Boufettal H, Essodegui F, Noun M, Hermas S, Samouh N: Idiopathic granulomatous mastitis: a report of twenty cases. Diagn Interv Imaging 2012;93:586-96.

18 Going JJ, Anderson TJ, Wilkinson S, Chetty U: Granulomatous lobular mastitis. J Clin Pathol 1987;40:535-40.

19 Stary CM, Lee YS, Balfour J: Idiopathic granulomatous mastitis associated with corynebacterium sp. infection. Hawaii Med J 2011;70:99-101.

20 Renshaw AA, Derhagopian RP, Gould EW: Cystic neutrophilic granulomatous mastitis: an under- appreciated pattern strongly associated with grampositive bacilli. Am J Clin Pathol 2011;136:424-7.

21 Pereira FA, Mudgil AV, Macias ES, Karsif K: Idiopathic granulomatous lobular mastitis. Int $\mathrm{J}$ Dermatol 2012;51:142-51.

22 Imoto S, Kitaya T, Kodama T, Hasebe T, Mukai K: Idiopathic granulomatous mastitis: case report and review of the literature. Jpn J Clin Oncol 1997; 27:274-7.

23 DeHertogh DA, Rossof AH, Harris AA, Economou SG: Prednisone management of granulomatous mastitis. N Engl J Med 1980;303:799-800.

24 Akbulut S, Yilmaz D, Bakir S: Methotrexate in the management of idiopathic granulomatous mastitis: review of 108 published cases and report of four cases. Breast J 2011;17:661-8.

25 Seo HR, Na KY, Yim HE, Kim TH, Kang DK, Oh KK, Kang SY, An YS, Chun M, Kim W, Park RW, Jung YS, Kim KS: Differential diagnosis in idiopathic granulomatous mastitis and tuberculous mastitis. J Breast Cancer 2012;15:111-8.

26 Kok KY, Telisinghe PU: Granulomatous mastitis: presentation, treatment and outcome in 43 patients. Surgeon 2010;8:197-201.

27 Diesing D, Axt-Fliedner R, Hornung D, Weiss JM, Diedrich K, Friedrich M: Granulomatous mastitis. Arch Gynecol Obstet 2004;269:233-6.

28 Vinayagam R, Cox J, Webb L: Granulomatous mastitis: a spectrum of disease. Breast Care (Basel) 2009;4:251-4.

29 Baslaim MM, Khayat HA, Al-Amoudi SA: Idiopathic granulomatous mastitis: a heterogeneous disease with variable clinical presentation. World J Surg 2007;31:1677-81.

30 Akbulut S, Arikanoglu Z, Senol A, Sogutcu N, Basbug M, Yeniaras E, Yagmur Y: Is methotrexate an acceptable treatment in the management of idiopathic granulomatous mastitis? Arch Gynecol Obstet 2011;284:1189-95. 